\title{
An epidemiological study of the relative importance of damp housing in relation to adult health
}

\author{
Julie Evans, Sophie Hyndman, Sarah Stewart-Brown, David Smith, Sophie Petersen
}

\begin{abstract}
Study objective-To examine the association between damp housing and adult health, taking into account a wide range of other factors that may influence health and could confound this relation.

Participants and setting-A general population sample of adults, aged 18-64, from Oxfordshire, Buckinghamshire, Berkshire and Northamptonshire.

Design-Secondary analysis of responses to a postal questionnaire survey carried out in 1997 with a $64 \%$ response rate $(8889$ of 13 800). Housing dampness was assessed by self report. Health was measured by responses to a series of questions including presence of asthma and longstanding illness generally, use of health services and perceived health status (the SF-36). The effect of damp was examined using the $\chi^{2}$ test and one way analysis of variance. Significant associations with the various health outcomes were further explored taking into account 35 other housing, demographic, psychosocial and lifestyle variables using stepwise
\end{abstract} logistic and linear regression.

Main results-Bivariate analyses indicated that damp was associated with the majority of health outcomes. Regression modelling however, found that being unable to keep the home warm enough in winter was a more important explanatory variable. Worry about pressure at work and to a lesser extent about money, showed an independent association with perceived health status equal to or greater than that of the housing environment, including cold housing, and that of health related lifestyles.

Conclusions-This study shows that being unable to keep the home warm enough in winter is more strongly associated with health outcomes than is damp housing. However, as cold and damp housing are closely related, it is likely that their combined effects are shown in these results. The importance of worry as an independent predictor of health status needs testing in other studies. Its prevalence and relative importance suggest that it may be a significant determinant of public health. (F Epidemiol Community Health 2000;54:677-686)

Several studies document a higher prevalence of ill health, particularly respiratory symptoms ${ }^{12}$ and longstanding illness ${ }^{3}$ in adults living in damp housing. In children, consistent associations have been shown between damp housing and ill health, in particular respiratory symptoms. ${ }^{1-7}$ The relation between damp housing and ill health is complex as many factors associated with poor housing also affect health. ${ }^{8}$ Teasing out specific associations from this "social complex" is difficult. A number of studies have succeeded in accounting for some potential confounding variables, by design or analysis, or both, ${ }^{1-3610}$ and there is now evidence that the relation between damp housing and ill health is causal. For example, the association has been shown consistently in different populations. ${ }^{71-15}$ Several studies have demonstrated a dose response relation between severity of damp and prevalence of health problems. ${ }^{1261516}$ Also, the association between damp housing and some aspects of health is biologically plausible through the effects of house dust mites ${ }^{17}$ and moulds, ${ }^{18}$ which are associated with a variety of allergic diseases including asthma. ${ }^{17}$ 19-24 Although the mechanism underlying the relation between other illnesses and damp is less clear, it has been suggested that fungal toxins may be involved in causing a variety of symptoms, including those that are non-respiratory ${ }^{1}$ (quoting May et $a l^{25}$ ). Alternatively, the wide range of health problems implicated, and their different aetiologies suggests that damp housing may create general susceptibility to poor health, by mechanisms that are not yet understood.

The third Oxford Healthy Life Survey (OHLS3) was commissioned by the Directors of Public Health for Berkshire, Buckinghamshire, Northamptonshire and Oxfordshire primarily to obtain information about key determinants of health. It provides a unique opportunity to examine the association between damp housing and health while accounting for a range of other variables not always available in housing and health studies. The survey measured health in a number of ways and collected data on a range of potential confounding factors.

\section{Methods}

The OHLS3 questionnaire was administered by post, in 1997, to a randomly selected sample of 14868 adults aged 18 to 64 years living in Berkshire, Buckinghamshire, Northamptonshire and Oxfordshire. The methodology has been described elsewhere. ${ }^{26}$ Ethical approval was granted by the local research ethics committee. A secondary analysis was undertaken of the 8889 responses to this survey. 
The OPCS General Household Survey question on longstanding illness accompanied by a checklist of conditions (including asthma) developed from responses to a previous survey:

"Do you have any longstanding illness, disability or infirmity (anything that has affected your work or other regular daily activities over a period of time or is likely to affect you over a period in the future)".

"Please circle the numbers that best describe your longstanding illness, disability or infirmity. (If you have more than one longstanding illness, disability or infirmity please circle all the numbers that apply.)"

Use of health services (4 items):

number of visits to the GP's surgery in the last 12 months; visited outpatients department in the last 3 months; visited casualty department in the last 3 months; hospital inpatient (day case or longer) in the last 12 months.

SF-36 (8 multi-item dimensions): physical functioning; social fuctioning; role limitations due to physical problems; role limitations due to emotional problems; mental health; energy and vitality; pain; general health perception.

NB For each SF-36 variable, item scores are coded, summed, and transformed onto a scale from 0 (worst possible health state) to 100 (best possible health state).

Figure 1 Health outcome measures.

The health outcomes used in this analysis were: prevalence of longstanding illness, and asthma specifically; use of health services; and the anglicised version of the SF- $36^{27}$ (see fig 1 ). Initially, bivariate associations between damp housing and each health outcome were examined using the $\chi^{2}$ test or one way analysis of variance. These associations were further examined in the context of 35 independent variables (see fig 2) using stepwise logistic or linear regression modelling. Number of visits to the GPs' surgery was transformed from a five category variable into a dichotomous variable comparing those who visited the surgery four or more times in the past year (that is, more often than the OHLS3 average) with those who visited less often or never. Six logistic regression models were undertaken, one for longstanding illness generally, one for asthma specifically, and four for aspects of health service use. Eight linear regression models were undertaken for health status (one for each dimension of the SF-36). For all regressions, a forward stepwise method was used, so each variable was added to the model in order of the significance of its score statistic. Variables were entered into the models at the $5 \%$ level of significance $(p<0.05)$, however only those variables that were highly statistically significant $(p<0.01)$ are shown in the tables. In the following sections, the term significant refers to $\mathrm{p}<0.01$. All analyses were undertaken using SPSS version 7.5 .

\section{Results}

A response rate of $64 \%$ (8889 of 13800 ) was achieved for the OHLS3 after 1068 deletions were made mainly because of "unknown addressees". A comparison with the 1991 census showed that respondents were broadly representative of the general population. ${ }^{26}$ Characteristics of respondents are shown in table 1 .

\section{ASTHMA, LONGSTANDING ILLNESS AND HEALTH} SERVICE USE

In the bivariate analysis, damp housing was associated both with longstanding illness and with asthma specifically (see table 2 ). It was also associated with four or more visits to the GP's surgery in the past year, use of hospital casualty and of outpatient departments in the past three months. A linear dose response relation was demonstrated for all these associations $(p<0.001)$ except for use of hospital inpatients, where $\mathrm{p}=0.048$.

Despite these initial results, damp housing was not significant in any of the six logistic regression models (see table 3). However, being unable to keep the home warm enough in winter was associated with asthma, longstanding illness generally, visits to the GP's surgery and outpatient departments. Those who had difficulty keeping their home warm enough "most of the time" were nearly twice as likely to visit the surgery four or more times (odds ratio $1.8,95 \%$ confidence intervals $1.2,2.7$ ), and twice as likely to use outpatient departments (odds ratio 2.1, 95\% confidence intervals 1.4, 3.3) as those who never experienced this 
problem. The distribution of the regression coefficients provides evidence of a dose response relation.

Other variables consistently significant in these models were age, employment status and sex of respondent. Age was significant in five out of six models. Asthma, use of hospital inpatients and casualty were more common in younger people, while longstanding illness generally and use of outpatient departments were more common in older people. Sex of respondent was significant in five, and employment status in four of the six models. Women were more likely than men to report a longstanding illness, visit their GP's surgery four or more times, be admitted as an inpatient, or use outpatient departments, while men more commonly used casualty departments. Being unable to work because of illness/ disability, or being retired, were the most important categories of employment status associated with negative health outcomes.

The "smoking" variable was significant in three models but the effect was attributable to being an ex-smoker rather than a current smoker. The former was associated with asthma, longstanding illness generally, and visits to the GP's surgery. Worry about pressure at work featured in three of the six models, and the regression coefficients are strongly suggestive of a dose response relation between increased worry and the prevalence of illness and greater health service use.

\section{HEALTH STATUS}

In the bivariate analysis, damp housing was associated with all eight dimensions of the SF-36 in a linear dose response relation $(\mathrm{p}<0.001)$. Those living in damp housing experienced poorer health status than those not in damp housing. The variables that were significant in the eight linear regression models varied according to SF-36 dimension (see table 4). Damp housing was only associated with "health perception", and only when reported as "more of a nuisance than a problem". The most important housing variable was cold housing, associated with poorer health status on all eight dimensions $(p<0.001)$. Being unable to keep the home warm enough "quite

\begin{tabular}{|c|c|}
\hline Demographic & Housing and local environment \\
\hline Age & Damp housing \\
\hline Sex of respondent & $\begin{array}{l}\text { "Is damp or condensation a serious problem in your home? } \\
\text { (Please do not include just normal condensation on }\end{array}$ \\
\hline Social class (based on own occupation & windows)" (serious problem, minor problem, no problem) \\
\hline $\begin{array}{l}\text { and coded according to the Registrar } \\
\text { General's classification) }\end{array}$ & $\begin{array}{l}\text { Cold housing } \\
\text { "Are there times in the winter when you cannot keep your }\end{array}$ \\
\hline Marital status & home warm enough?" (never, only occasionally, quite \\
\hline Employment & (1) \\
\hline $\begin{array}{l}\text { Age left full time education } \\
\text { Ethnic group }\end{array}$ & $\begin{array}{l}\text { Housing tenure } \\
\text { (privately owned (mortgage), privately owned (outright), } \\
\text { rented from council, rented from housing } \\
\text { association/charitable trust, rented privately, other) }\end{array}$ \\
\hline $\begin{array}{l}\text { Psychosocial } \\
\text { How often do you worry about: }\end{array}$ & $\begin{array}{l}\text { Space in the home } \\
\text { (very crowded, slightly crowded, just about right, rather too } \\
\text { large, much too large) }\end{array}$ \\
\hline $\begin{array}{l}\text { - money } \\
\text { - job security } \\
\text { - pressure at work }\end{array}$ & $\begin{array}{l}\text { "Do you believe any of the following to be a problem in the } \\
\text { area where you live?" (serious problem, minor problem, no } \\
\text { problem) }\end{array}$ \\
\hline Lifestyle & - vandalism \\
\hline $\begin{array}{l}\text { Smoking } \\
\text { ( } \geq 1 \text { per day, in the past, never) }\end{array}$ & $\begin{array}{l}\text { - assaults and muggings } \\
\text { - speeding traffic }\end{array}$ \\
\hline Passive smoking & - discarded needles and syringes \\
\hline ("How often do you breathe other & - nuisance from dogs \\
\hline people's smoke, as in 'passive smoking'?") & - smells and fumes \\
\hline Alcohol consumption & - noise \\
\hline ("Do you ever drink alcoholic drinks?") & - litter and rubbish \\
\hline Vigorous physical exercise & - disturbance by neighbours \\
\hline ("On average, how often do you & - lack of open spaces \\
\hline $\begin{array}{l}\text { undertake vigorous sport or recreational } \\
\text { activities which make you breathless? }\end{array}$ & - poor street lighting \\
\hline (e.g. jogging, aerobics, football, tennis))" & - poor publc transport \\
\hline Diet & - uneven or dangerous pavements \\
\hline $\begin{array}{l}\text { vegetables (including frozen) and salad } \\
\text { do you eat each day?") }\end{array}$ & $\begin{array}{l}\text { " How much do you want to move from your local area?" } \\
\text { (very strongly want to move, prefer to move, don't mind, } \\
\text { prefer not to move, very strongly want to stay) }\end{array}$ \\
\hline
\end{tabular}

Figure 2 Independent variables. 
Table 1 Characteristics of respondents

\begin{tabular}{|c|c|c|}
\hline Characteristic & Number & Per cent \\
\hline Men & 3863 & 44 \\
\hline Women & 4938 & 56 \\
\hline \multicolumn{3}{|l|}{ Age } \\
\hline $18-24$ & 980 & 11 \\
\hline $25-34$ & 2003 & 23 \\
\hline $35-44$ & 2129 & 24 \\
\hline $45-54$ & 2112 & 24 \\
\hline $55-64$ & 1529 & 18 \\
\hline \multicolumn{3}{|l|}{ Social class } \\
\hline I & 450 & 6 \\
\hline II & 2468 & 32 \\
\hline IIIN & 2118 & 28 \\
\hline IIIM & 1218 & 16 \\
\hline IV & 1141 & 15 \\
\hline $\mathrm{V}$ & 312 & 4 \\
\hline Longstanding illness (all types) & 3701 & 42 \\
\hline Asthma & 621 & 7 \\
\hline Used casualty department (last 3 months) & 479 & 5 \\
\hline Used outpatients department (last 3 months) & 1410 & 16 \\
\hline Hospital inpatient (last year) & 998 & 11 \\
\hline \multicolumn{3}{|l|}{ Visited GP's surgery (last year) } \\
\hline never & 1256 & 14 \\
\hline once & 2018 & 23 \\
\hline $2-3$ times & 3200 & 36 \\
\hline $4-5$ times & 1148 & 13 \\
\hline 6 or more times & 1209 & 14 \\
\hline Damp housing (serious problem) & 109 & 1 \\
\hline Damp housing (nuisance) & 812 & 9 \\
\hline Cold housing (most of the time/quite often) & 686 & 8 \\
\hline Crowded home (very crowded/slightly crowded) & 1361 & 15 \\
\hline Desire to move away (very strong/prefer to) & 1310 & 15 \\
\hline Speeding traffic (serious problem) & 1401 & 16 \\
\hline Poor public transport (serious problem) & 1140 & 13 \\
\hline Burglaries (serious problem) & 958 & 11 \\
\hline All other environmental factors (serious problem) & & $\leqslant 7$ \\
\hline Worry about money (a lot/all the time) & 2284 & 26 \\
\hline Worry about pressure at work (a lot/all the time) & 1901 & 22 \\
\hline Worry about job security (a lot/all the time) & 837 & 10 \\
\hline SF-36 dimension & Mean score & $S D$ \\
\hline energy and vitality & 58 & 20 \\
\hline general health perception & 71 & 20 \\
\hline mental health & 72 & 18 \\
\hline pain & 79 & 23 \\
\hline physical functioning & 88 & 20 \\
\hline role limitation mental & 86 & 21 \\
\hline role limitation physical & 87 & 22 \\
\hline social functioning & 83 & 23 \\
\hline
\end{tabular}

often" and "most of the time" were associated with poorer health status than that of being unable to keep the home warm "only occasionally".

Other variables associated with all eight dimensions were employment status, vigorous exercise, worry about money and about work pressure. The most important categories of employment status were being unable to work because of illness/disability, and retired, compared with being in full time employment. Never taking vigorous exercise was associated with poorer health status when compared with taking vigorous exercise five or more times per week. Where more than one category was significant, the distribution of the regression coefficients is strongly suggestive of a dose response relation. Similarly, there is strong evi- dence of dose response between poorer health status and more frequent worry about money and work pressure.

\section{Discussion}

RELATIVE IMPORTANCE OF DIFFERENT VARIABLES From the point of view of their consistent predictive value in the models, the most important factors relating to health were employment status, cold housing, and sex of respondent, each associated with 12 of the 14 outcomes. By far the largest effect on health was attributable to inability to work because of illness/disability. Because of the possibility that this category was determining the importance of employment status in the analyses, the modelling was repeated omitting this group $(n=318)$. However, this resulted in no major changes to the models, suggesting that other occupational categories were also important predictors of ill health, namely those not involving paid employment. Being unemployed (seeking work), caring for home or family (not seeking work), or retired were associated with seven, nine and 12 health outcomes respectively, although the size of their effects on health were small compared with that of being unable to work.

In relation to cold housing, it is notable that the effect on health of being unable to keep the home warm enough "quite often" or "most of the time" was in almost all models greater than that of any of the health related lifestyles including vigorous exercise and smoking (either current or previously).

In relation to sex of respondent, the finding that women's health was poorer than that of men in 11 of the 12 models where sex was significant (the exception being the use of hospital casualty departments) is consistent with published literature. ${ }^{28}$

The next most frequently significant variable was worry about pressure at work, associated with 11 outcomes. In terms of relative magnitude of effect on health outcomes (as indicated by the regression coefficients), worry about pressure at work and about money (associated with nine outcomes) were as important, or more important than either cold housing or health related lifestyles. The importance of these "worry" variables in relation to mental health is not surprising, but it is notable that their effect was greater than that of problems in the local environment, for example poor public transport, smells and fumes, noise, lack of open spaces, and vandalism. While respondents were asked whether they believed the area where they lived suffered

Table 2 Per cent of respondents with longstanding illnesses and utilising NHS services stratified by severity of damp housing

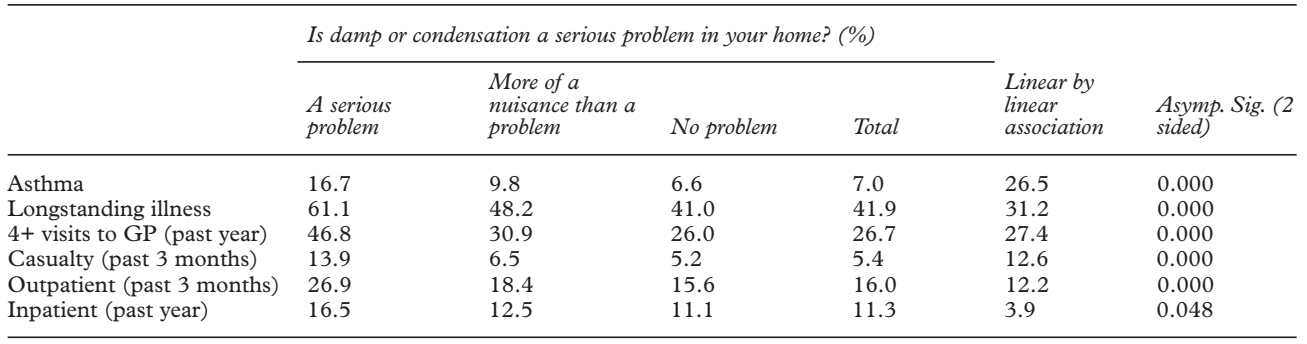




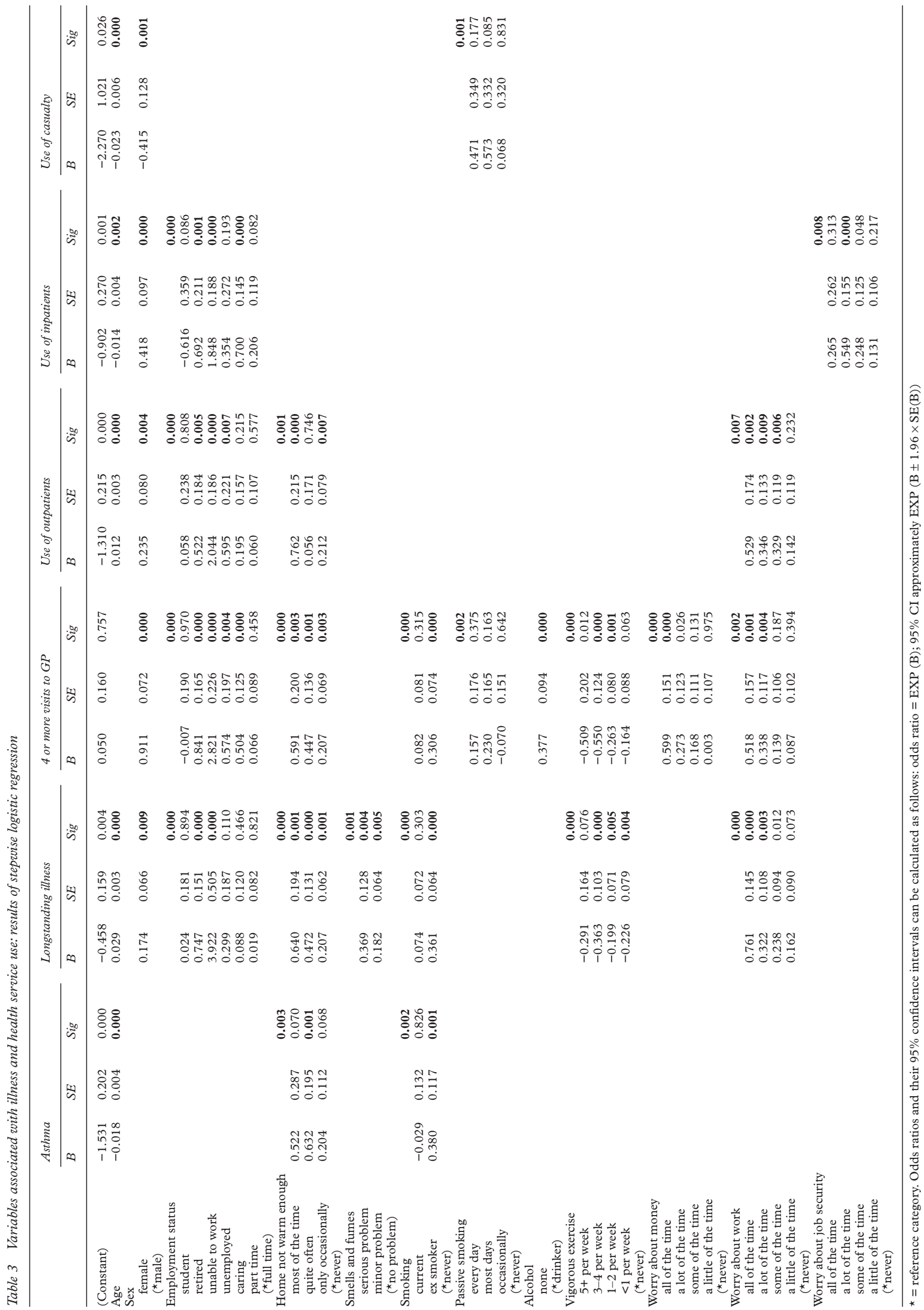




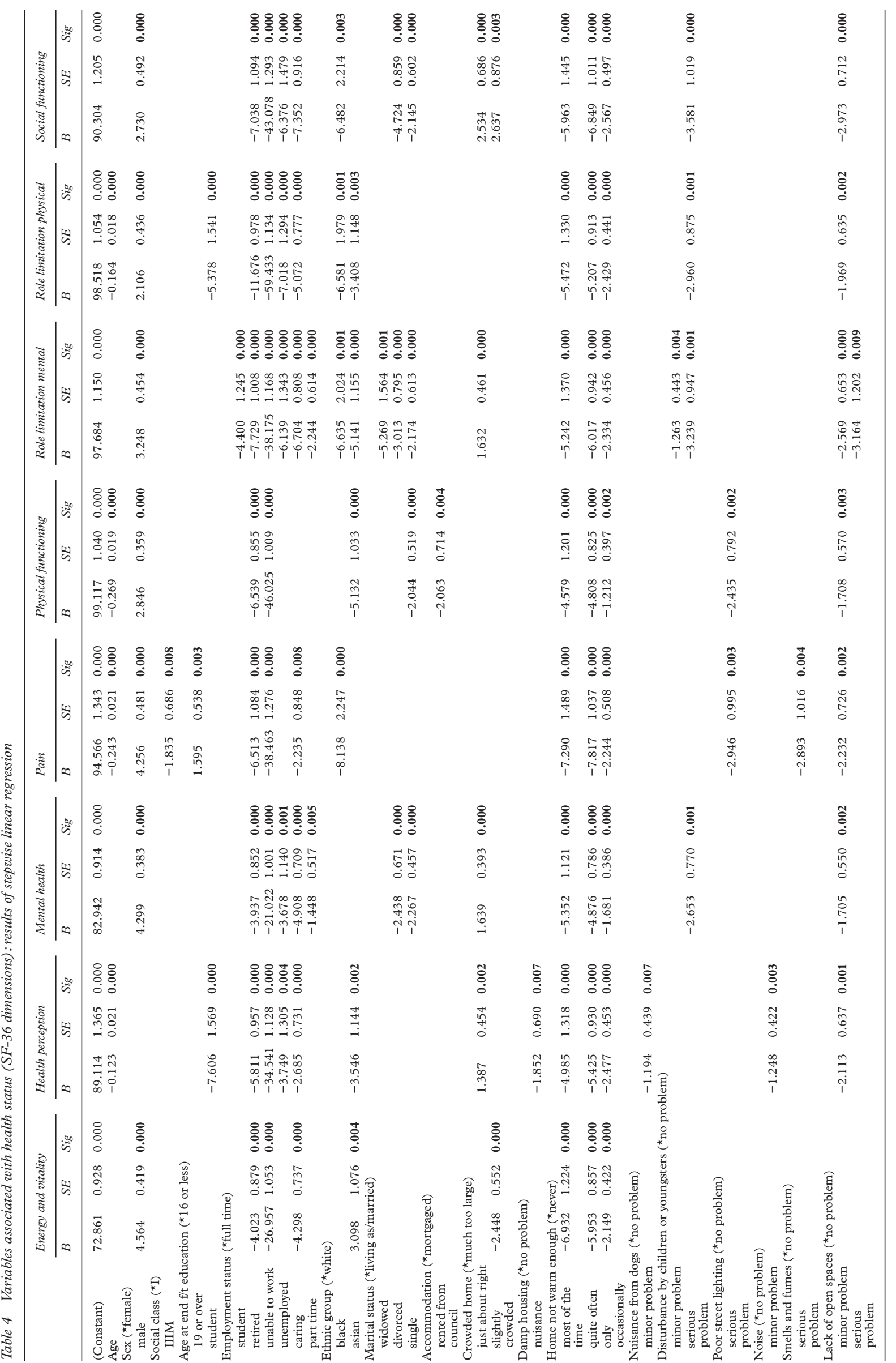




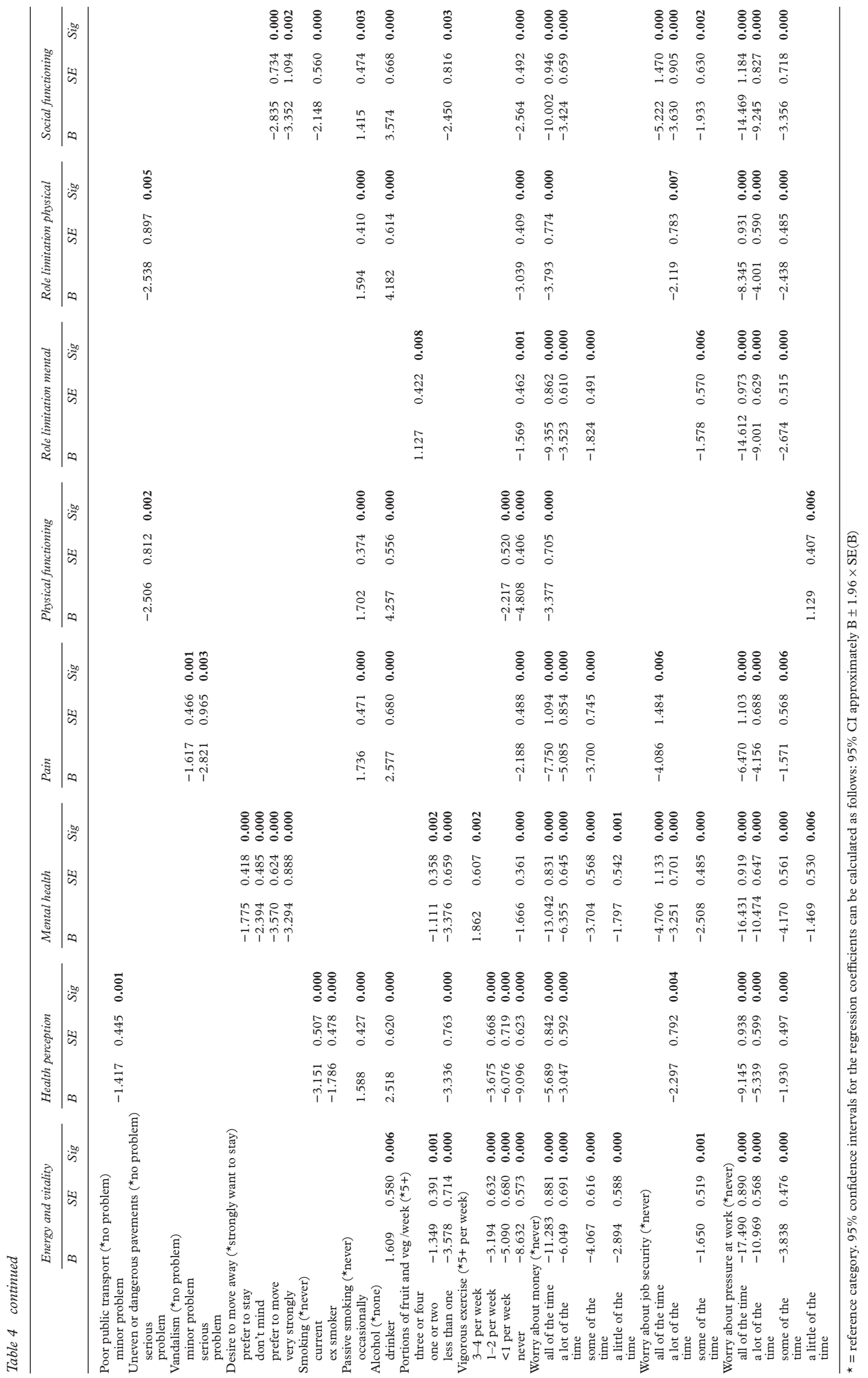


from the latter problems, rather than how often they worried about them, as was the case with concern about money and pressure at work, in both cases respondents were offering a subjective impression. Given the greater prevalence in this survey of work and money worries compared with housing problems, these models suggest the former may be more important from a public health perspective.

Vigorous physical exercise was associated with 10 health outcomes, and respondent age with nine outcomes. As might be expected, the results show that regular vigorous exercise is associated with perceived good health and high energy levels. Both this and the apparent protective effect of any vigorous activity on longstanding illness may be an outcome rather than a cause. The relatively low impact on current health attributable to health related lifestyles other than physical activity is likely to be attributable to the fact that the detrimental impact of health related lifestyles may only be apparent in the long term.

COLD AND DAMP HOUSING

The most important housing variable seemed to be the perceived temperature of the home, not damp. Damp and cold housing are often related, and bivariate analyses of our data indicate a linear association between these two variables $\left(\chi^{2}\right.$ test, $\left.p<0.001\right)$. It is therefore possible that reported cold housing reflects the combined effects of reduced temperatures and increased humidities on health. However, it is clear that when both damp and cold housing are entered into the multivariate models, it is the cold that predominates.

Despite a considerable literature on housing dampness, cold housing has been neglected, possibly because cold and damp are so interrelated. Although some housing and health studies have examined aspects of heating these variables have been included primarily as potential sources of pollutants (for example, Spengler et $\left.a l^{15}\right)$. One study modelled the effects of perceived cold and dampness together. ${ }^{1}$ Associations between damp/mouldy housing and number of symptoms persisted when perceived cold and other housing factors were accounted for. Another study included "bedroom unheated" and "bedroom window left open at night" in a logistic regression model along with reported damp and mould in relation to health. ${ }^{12}$ Here, reported mould and "bedroom window left open at night" both contributed to parental reports of wheeze. These variables can only be considered as proxies for perceived temperature in the home. The cold housing variable in the OHLS3 is also only a proxy, and clearly contains an economic component as some people on low incomes may inadequately heat their homes to minimise heating costs. Although our cold housing variable was based on perceived rather than objectively measured cold, it may be an equally valid predictor of ill health as the latter could be associated with feeling cold rather than the actual temperature. The possible impact of feeling as compared with being cold does not seem to have received consideration.
Cold housing may affect health in its own right. The dangers of very low temperatures, in the form of hypothermia, are well established, ${ }^{29}$ but there is little information on less extreme temperatures. Evidence suggests that cooling is associated with changes in blood pressure and viscosity. ${ }^{30}$ Rises in blood pressure in elderly people are seen at $12^{\circ} \mathrm{C}$. ${ }^{31}$ Also, low indoor temperatures may damage the lungs indirectly by reducing resistance to infections secondary to colds and influenza. ${ }^{32}$ Seasonal mortality has been discussed in relation to cold housing ${ }^{33}$ and Raw and Hamilton ${ }^{34}$ place "hygrothermal conditions" as one of the most important risk factors for health related to housing. The results of our study support this.

WORRY AS A CAUSE OF ASPECTS OF POOR HEALTH The strength of association between physical and mental health and worry about work and money was a surprise finding and needs replicating in other datasets. The importance of worry relative to other factors of current public health concern suggests that such studies are urgent. Overall "emotional health problems" seem to be more common than physical health problems in this age group (18-64 years)..$^{35}$ While they seem to be as disabling as physical health problems ${ }^{35}$ they receive less attention from both public health and treatment services. Evidence is mounting that such problems may cause physical illness, in addition to being important in their own right. For example, studies exist that demonstrate that emotional distress from low job control, ${ }^{36}$ examinations $^{37}$ and life events ${ }^{38}{ }^{39}$ can create susceptibility to physical illness and increase mortality. Animal studies provide evidence to support one possible causal mechanism via the immune response..$^{40} 41$ The long term impact on health of health related lifestyles provides the basis for an alternative, potentially complementary, causal hypothesis. Smoking, drinking alcohol and consuming high fat foods are all valued by the public for their ability to relieve emotional distress. ${ }^{42}$

This survey did not collect data on whether cold or damp housing worried respondents. However, if worry about work or money creates general susceptibility to physical and mental health problems, worry about damp or cold housing might do so too. Research into the impact of housing on health has concentrated on mechanisms involving external biological agents and ignored the potential importance of psychosocial pathways, even though the latter offer a plausible explanation of the impact of housing on a range of very different health problems.

\section{LIMITATIONS OF THE STUDY}

The response rate of $64 \%$ limits the extent to which definitive conclusions can be drawn. However, as no major biases among respondents were found and as the relations between variables found in the responding group should not have been affected by the response rate, our conclusions about the relative importance of the different variables should be robust. 
Other limitations arise from the fact that the dataset was collected primarily for other purposes. For example, no data were collected on some potentially important variables in the analysis concerning asthma, such as pet ownership.

In addition, the survey was restricted to adults aged 18 to 64 . As the elderly experience a high degree of ill health and many live in poor housing, their omission could have biased our results. However, it could be argued that their inclusion would strengthen rather than weaken associations between poor housing and health. Within our sample of working age adults, it is younger, rather than older people who tend to report the worst housing problems. Those aged 18-33 were most likely to report either damp housing as "a serious problem" or cold housing "most of the time", while those aged 50-64 were least likely to report these problems (linear by linear association, $\mathrm{p}<0.01$ for both). It is therefore important to evaluate the possible impact of housing problems in younger, as well as older, age groups.

Cross sectional surveys cannot determine the direction of relations between variables, although evidence of dose response is suggestive of causality. For some associations in our data, ill health may be a cause rather than, or as well as, an outcome of the characteristic; for example the association between ill health and employment status. ${ }^{43}$ There is evidence both that unemployment causes avoidable morbidity and premature mortality, ${ }^{44}$ and that people with psychological ill health are more likely to remain unemployed. ${ }^{45}$ Similarly, the association between ill health and retirement in our study could reflect either an effect of prior ill health on the decision to retire, or a result of retirement. There is some evidence that women who care for children or for sick family members experience more symptoms of minor illness than others. ${ }^{46}{ }^{47}$ If poor housing is a cause of ill health it could be argued that those who stay at home during the day are more likely to notice and be affected by poor housing conditions such as damp or cold.

Other associations of this type are those with ill health and being an ex-smoker, and worrying about work. It is well recognised that many smokers quit because they have become ill and therefore that illness tends to be associated with being an ex-smoker more than with being a current smoker. Similarly, being unwell can prevent physical activity and exacerbate worry about pressure at work.

Studies of damp housing and health have tried to overcome the possibility of reporting bias by including both objective and subjective measures of health and housing (see review by Hyndman $^{48}$ ), but for logistical reasons no objective measures were used in this survey. However, self reported health and housing have been shown to be associated with objectively measured health and housing respectively. ${ }^{10}$ General health perception has also been shown in longitudinal surveys to be predictive of mortality. ${ }^{49}$ In our survey, the questions on housing and health were widely separated in the questionnaire with those on health being
KEY POINTS

- Cold housing is more strongly associated with ill health than is damp housing when the two are examined together.

- Cold and damp housing are closely related.

- Cold housing is associated with a wide range of health outcomes.

- The importance of reported cold over damp housing merits further consideration.

- Cold housing is less strongly associated with health than are some other variables, notably "worries" about work and money.

reported before those on housing. Nevertheless, it would be advantageous to confirm our findings in datasets that include both objective and subjective measures of damp and cold housing.

POTENTIAL COST OF POOR HOUSING TO THE NHS The cost to the NHS of treating conditions caused by poor housing has been estimated as $£ 2$ billion per year. This was based on a study that found respondents in poor housing used health services $50 \%$ more than average..$^{50}{ }^{51}$ Our finding that cold housing is associated with a doubling of the use of outpatient departments and GP surgeries suggests that the cost to the NHS could be even higher.

\section{Conclusion}

Epidemiological studies tend to focus on one particular area, and collect data accordingly. The strength of this study has been its ability to examine the relation between damp housing and health in the context of a range of environmental, demographic, psychosocial and lifestyle variables. Taking these variables into account, those most consistently related to health are: employment status, cold housing, worry about pressure at work, sex of respondent, and vigorous physical exercise. Particularly interesting are the apparent predominance of "cold housing" over damp when the two are entered into models together, and the significance of worry about work and money. The results concerning cold and damp do not mean that damp housing is unimportant. It is possible that it is the combined effects of cold, damp housing that is being demonstrated. The relative prevalence and importance of "worry" in relation to both physical and mental health in this study is notable. This raises important issues concerning the possible direct effects of emotional distress on health in general, as well as its role as a possible mediator in relations between housing and health.

The authors would like to acknowledge with thanks: the Directors of Public Health for Buckinghamshire, Berkshire, Northamptonshire and Oxfordshire, who funded the OHLS3 itself; specialists in health promotion and public health in these four counties who supported the survey through the Advisory Group; Viv Peto and other members of the Health Services Research Unit for their help in administering the survey; all the Research Unit for their help in administering the survey; all the
members of the public who took time to complete the OHLS3 
questionnaire; and the Department of Health/Department of Environment, Transport and the Regions who funded the specific analyses reported in this paper.

Funding: this work was funded by a Department of Health Department of Environment, Transport and the Regions initia-
tive, together with the Directors of Public Health in Oxfordtive, together with the Directors of Public Health in Oxford
shire, Buckinghamshire, Berkshire and Northamptonshire. Conflicts of interest: none.

1 Platt SD, Martin CJ, Hunt SM, et al. Damp housing, mould growth, and ste. BMF growth, and sym

2 Dales RE, Burnett R, Zwanenburg H. Adverse health effects among adults exposed to home dampness and molds. American Review of Respiratory Disease 1991;143:505-9.

3 Packer CN, Stewart-Brown S, Fowle S. Damp housing and adult health: results from a lifestyle survey in Worcester England. $\mathcal{F}$ Epidemiol Community Health 1994;48:555-9.

4 Martin CJ, Platt SC, Hunt SM. Housing conditions and ill health. BMF 1987;294:1125-7.

5 Strachan DP. Damp housing and childhood asthma: validation of reporting of symptoms. BMF 1988;297:1223-6.

6 Dales RE, Zwanenburg H, Burnett R, et al. Respiratory health effects of home dampness and molds among Canadian children. Am f Epidemiol 1991;134:196-203.

7 Melia RJW, Florey CV, Morris RW, et al. Childhood respiratory illness and the home environment. II: association tory ilness and the home environment. II: association between respiratory illness and nitrogen dioxide, tempera-
ture and relative humidity. Int f Epidemiol 1982;11:164-9.

8 Keithley J, Byrne D, Harrisson S, et al. Health and housing Keithley J, Byrne D, Harrisson S, et al. Health and housing conditions in public sector
London 1984;98:344-53.

9 Stein L. Tuberculosis and the "social complex" in Glasgow. British fournal of Social Medicine 1952;6:1-48.

10 Hyndman SJ. Housing dampness and health amongst British Bengalis in East London. Soc Sci Med 1990;30:131-41.

1 Burr ML, St Leger AS, Yarnell JWG. Wheezing, dampness and coal fires. Community Medicine 1981;3:205-9.

12 Strachan DP, Elton RA. Relationship between respiratory morbidity in children and the home environment. Fam Pract 1986;3:137-42.

13 Waegermaekers $M$, van Wageningen $\mathrm{N}$, Brunekreef $\mathrm{B}$, et al. Respiratory symptoms in damp homes. Allergy 1989;44: 192-8.

14 Dijkstra L, Houthuijs D, Brunekreef B, et al. Respiratory health effects of the indoor environment in a population of Dutch children. American Review of Respiratory Diseases 1990;142:1172-8.

15 Spengler J, Neas L, Nakai S, et al. Respiratory symptoms and housing characteristics. Indoor Air 1994;4:72-82.

16 Williamson IJ, Martin CJ, McGill G, et al. Damp housing and asthma: a case-control study. Thorax 1997;52:229-34

7 Fain A, Guerin B, Hart BJ. Mites and allergic disease. Varennes en Argonne, France: ALLERBIO, 1990

18 Institution of Environmental Health Officers. Mould fungal spores - their effects on health, and the control, prevention and treatment of mould growth in dwellings. Vol 1. Environmental Health Professional Practice. London: IEHO, 1985: chapter II.

19 Platts-Mills TAE, Chapman MD. Dust mites: immunology, allergic disease, and environmental control. 7 Allergy Chin Immunol 1987;80:755-75.

20 Sporik R, Holgate ST, Platts-Mills TAE, et al. Exposure to house-dust mite allergen (Der p I) and the development of asthma in childhood. N Engl f Med 1990;323:502-7.

21 Lau S, Falkenhorst G, Weber A, et al. High mite-allergen exposure increases the risk of sensitisation in atopic exposure increases the risk of sensitisation in atopic
children and young adults. F Allergy Clin Immunol 1989;84: children

22 Korsgaard J. Mite asthma and residency. American Review of Respiratory Disease 1983;128:231-5.

23 Salvaggio J, Aukrust L. Mold-induced asthma. 7 Allergy Clin Immunol 1981;68:327-46.

24 Gravesen S. Fungi as a cause of allergic diseases. Allergy 1989;34:135-54.

25 May JJ, Stallones L, Darrow D, et al. Organic dust toxicity (pulmonary mycotoxicosis) associated with silo unloading. Thorax 1986;41:919-23.
26 Doll H, Petersen S, Stewart-Brown S. Obesity and physical and emotional well-being: associations between BMI, chronic illness and the physical and mental components of the SF-36. Obes Res 2000;8:160-70.

27 Jenkinson C, Layte R, Wright L, et al. The U.K SF36: an analysis and interpretation manual. Oxford: Health Services Research Unit, 1996.

28 Hillier S. Women as patients and providers. In: Scambler G, ed. Sociology as applied to medicine. 3rd ed. London: Balliere Tindall, 1991.

29 Lowry, S. Housing and health. London: British Medical Journal Publications, 1991.

30 Keatinge WR, Coleshaw SRK, Cotter F, et al. Increases in platelet and red cell counts, blood viscosity, and arterial pressure during mild surface cooling: factors in mortality
from coronary and cerebral thrombosis in winter. $B M \mathcal{F}$ from coronary and

31 Collins KJ, Easton JC, Belfield-Smith H, et al. Effects of age on body temperature and blood pressure in cold environments. Clin Sci 1985;69:465-70.

32 Collins, KJ. Low indoor temperatures and morbidity in the elderly. Age Ageing 1986;15:212-20.

33 Boardman, B. Seasonal mortality and cold homes. Unhealthy housing: a diagnosis. University of Warwick: Institution of Environmental Health Officers/ Legal Research Institute conference, 1986. Watford: Watford Printers, 1986.

34 Raw GJ, Hamilton, RM. Building regulation and health. Garston: Building Research Establishment, 1995.

35 Stewart-Brown S, Layte R. Emotional health problems are the most important cause of disability in adults of working age: a study in the four counties of the old Oxford region. $\mathscr{f}$ Epidemiol Community Health 1997;51:672-5.

36 Bosma H, Marmot MG, Hemingway H, et al. Low job control and risk of coronary heart disease in Whitehall II (prospective cohort) study. BMF 1997;314:558-65.

37 Cohen S, Tyrrell DAJ, Smith AP. Psychological stress and susceptibility to the common cold. N Engl F Med 1991;325: 606-12.

38 Rosengren A, Orth-Gomer K, Wedel H, et al. Stressful life events, social support and mortality in men born in 1933 . BMF 1993;307:1 102-5.

39 Tennant CC, Palmer KJ, Langgeluddecke PM, et al. Life event stress and myocardial reinfarction: a prospective study. Eur Heart $\mathcal{F}$ 1994;15:472-8.

40 Wilkinson RG. Unhealthy societies: the afflictions of inequality. London: Routledge, 1996.

41 Brunner E. Stress and the biology of inequality. BMF 1997; 314:1472-5

42 Cameron D, Jones ID. An epidemiological and sociological analysis of alcohol tobacco and other drugs of solace. Community Medicine 1985;7:18-29.

43 Bartley M. Unemployment and ill health: understanding the relationship. F Epidemiol Community Health 1994;48:333-7.

44 Moser K, Goldblatt P, Fox J, et al. Unemployment and mortality. In: Goldblatt PO, ed. Longitudinal study: mortality and social organisation. London: HMSO, 1990

45 Claussen B, Bjorndal A, Hjort PF. Health and reemployment in a two year follow up of long term unemployed. F Epidemiol Community Health 1993;47:1418. 46 Popay J. "My health is all right, but I'm just tired all the
time": women's experience of ill health. In: Roberts H, ed. Women's health matters. London: Routledge, 1992.

47 Graham H. Women, health and the family. Hemel Hempstead: Wheatsheaf, 1984.

48 Hyndman S. Making connections between housing and health. In: Kearns R, Gesler S, eds. Putting health into place: landscape, identity and well-being. New York: Syracuse University Press, 1998.

49 Kaplan GA, Goldberg DE, Everson SA, et al. Perceived health status and morbidity and mortality: evidence from disease risk factor study. Int $\mathcal{f}$ Epidemiol 1996;25:259-65.

50 Carr-Hill RA, Coyle D, Ivens C. Poor housing: poor health? Unpublished report funded by the Department of the Environment: London, 1993. Quoted in Lawson R 1997 (reference 51)

51 Lawson R. Bills of health. Abingdon, Oxfordshire: Radcliffe Medical Press, 1997. 